\title{
Role of essential fatty acids on the reproductive success of the copepod Temora longicornis in the North Sea
}

\author{
Janna Peters ${ }^{1, *}$, Jörg Dutz $^{2}$, Wilhelm Hagen ${ }^{1}$ \\ ${ }^{1}$ Marine Zoology, University of Bremen, PO Box 330440, 28334 Bremen, Germany \\ ${ }^{2}$ Baltic Sea Research Institute, Warnemünde, Seestraße 15, 18119 Rostock, Germany
}

\begin{abstract}
This field study focused on the transfer of dietary fatty acids (FAs) into the eggs of Temora longicornis and assessed their potential for limiting egg production and egg viability. In situ egg production rates (EPRs), hatching success and FA profiles of females, as well as eggs, were determined and compared to food indicators, i.e. particulate organic carbon, particulate organic nitrogen and FAs of size-fractionated seston samples. Individual egg production ranged from 14 to 28 eggs female $\mathrm{e}^{-1} \mathrm{~d}^{-1}$, corresponding to weight-specific egg production rates (sEPRs) from 0.18 to 0.35 . Based on trophic marker FAs, T. longicornis most likely fed non-selectively. FA contents of eggs ranged from 2.6 to $4.3 \mathrm{ng} \mathrm{egg}^{-1}$ and correlated significantly with the FA content in seston (size class: 1 to $30 \mu \mathrm{m}$ ). Strong similarities in FA profiles of eggs and seston, as well as correlations of absolute FA levels, indicated only minor maternal regulation of egg composition. The significant increase in EPRs with an increasing diatom food supply, as indicated by correlation with 16:1(n-7) levels in seston and eggs, strongly compensated for the tendency to produce less viable eggs on a diatom-dominated diet. Egg viability was overall very high (77 to $94 \%$ ) at all our stations and did not relate to essential FA levels in the eggs, indicating that lipids were transferred in sufficient quantities. Thus, food quantity rather than quality determined the reproductive success of $T$. longicornis during our study. Stoichiometric comparisons between seston and egg composition suggested that nitrogen-containing compounds had a higher potential for limiting egg production during our study than essential FAs.
\end{abstract}

KEY WORDS: Essential fatty acids - Egg composition - Reproductive success - Food quality · Fatty acid transfer · Trophic markers

Resale or republication not permitted without written consent of the publisher

\section{INTRODUCTION}

Detailed knowledge of the processes regulating the reproductive success of copepods is a key in understanding and modelling their population dynamics. Apart from temperature influences, reproductive processes are mainly determined by food quantity and quality, such as cell size, digestibility, toxicity, as well as mineral and biochemical composition.

Several studies found egg production rates (EPRs) to correlate with rough proxies for food quantity such as chlorophyll $a$ or particulate organic carbon (POC) (Kleppel 1992, Maps et al. 2005). Others, in contrast, suggested a limitation by specific food components, such as essential amino (Helland et al. 2003) or fatty acids (FAs) (Pond et al. 1996, Hazzard \& Kleppel 2003). The potential of a single dietary compound to limit egg production implies, at least in times of low availability, a strong maternal regulation of its transfer into the eggs. Consequently, this will lead to a decrease in egg production in favour of a composition that meets minimum requirements for successful egg development (Anderson \& Pond 2000). In contrast, the FA composition of eggs has also been found to correspond to the composition of the ingested food (Ederington et al. 1995, Støttrup et al. 1999, Lacoste et al. 2001), and failure in egg development has thus been associated with diet deficiencies in essential FAs or with ratios of spe- 
cific FAs (Jónasdóttir et al. 2002, Hazzard \& Kleppel 2003, Tang \& Taal 2005). These observations suggest only a minor role for maternal regulation of egg production. These inherently conflicting mechanisms, affecting egg production and hatching success differently, are not easily assessed, since metabolic processes are intricate and subject to manifold internal and external variables.

The physiological requirements for successful embryogenesis of marine copepods are complex, yet poorly understood, and depend, along with polyunsaturated FAs (Shin et al. 2003), on a variety of other essential substances such as amino acids (Guisande et al. 2000) or sterols (Hasset 2004). The considerable importance of FAs is not only explained by their high energetic value, they are also indispensable for the maintenance of the structural and functional integrity of cell membranes (Sargent et al. 1999) and serve as precursors for eicosanoids, which are involved in hormonal regulation processes in marine invertebrates (Rowley et al. 2005). Further complexity arises from potential interactions between substances since chemical similarities, e.g. of DHA (docosahexaenoic acid) and EPA (eicosapentaenoic acid), can lead to competition in many chemical and physiological reactions (Sargent et al. 1999). Hence, not only the dietary levels of these compounds have to be considered, but also their relative amounts. While laboratory experiments offer a good opportunity to evaluate the role of food quantity versus food quality under controlled conditions, the established relationships might be of less relevance in the field due to the compensatory effects of dietary heterogeneity and selective feeding.

In order to assess the potential of specific FAs in determining egg production or hatching success in the field, it is essential not only to examine the relationship between seston composition and reproductive success, but also to evaluate the required FA amounts for egg production and coupling between food and egg quality. Our study aims to improve understanding of the influence of food quantity and quality on the egg production and egg composition of Temora longicornis, with a special focus on the role of essential FAs. T. longicornis is one of the most abundant copepods in the southern North Sea, with reproductive peaks in April and May (Halsband \& Hirche 2001, Arendt et al. 2005), and is an important grazer of the phytoplankton spring bloom (Dam \& Peterson 1993). Food-limited fecundity and growth of $T$. longicornis have frequently been observed (Maps et al. 2005), and a recent field study in the North Sea emphasised that the hatching success of T. longicornis is related to DHA levels and DHA:EPA ratios in the seston (Arendt et al. 2005). However, to our knowledge, there are no data on the FA profiles of T. longicornis eggs and their dietary dependencies.
We therefore determined in situ EPRs, hatching success and FA profiles of Temora longicornis females and eggs and compared them to food indicators, i.e. POC, PON (particulate organic nitrogen) and FAs. In order to examine the dietary selection of $T$. longicornis, we furthermore used signature FAs in the storage lipids. The use of biomarkers to characterise feeding on different taxonomic groups is well established, e.g. the assignment of $16: 1(n-7)$ and 20:5(n-3) to diatoms and 18:4(n-3) and 22:6(n-3) to dinoflagellates (Daalsgard et al. 2003), and can provide information on the recent feeding history of the females. In detail, the present study focused on the following questions: (1) Does $T$. longicornis feed selectively in order to obtain a diet of high quality? (2) Are there indications of maternal regulation of FA transfer into the eggs? (3) Was egg production limited by food quantity or by the abundance of specific FAs? (4) Does the FA composition of the eggs influence egg viability?

\section{MATERIALS AND METHODS}

Sampling and experiments. Experiments were performed during 2 cruises to the southern German Bight, North Sea (17 to 28 May, 1 to 8 July 2005), at 6 stations with no or low vertical stratification (Fig. 1). Zooplankton was collected in vertical tows $\left(0.2 \mathrm{~m} \mathrm{~s}^{-1}\right)$ from $20 \mathrm{~m}$ to the surface with a WP-2 net equipped with a solid cod end and $100 \mu \mathrm{m}$ mesh. When copepod abundance was low, an undulating towed multi-net (mesh size $335 \mu \mathrm{m}$, towed at $2.5 \mathrm{knots}$ and $0.2 \mathrm{~m} \mathrm{~s}^{-1}$ ) was used instead. Seawater for egg production experiments was collected with $10 \mathrm{l}$ Niskin bottles at 5 and $10 \mathrm{~m}$, or, at vertically stratified stations, at the depth of the thermocline, sieved through a submerged $48 \mu \mathrm{m}$ net and mixed equally. Within 10 to $20 \mathrm{~min}$ after capture, groups of 7 to 10 actively swimming females of Temora longicornis were transferred into 3 to 4 spawning chambers (1 l) with an inner compartment (0.7 l) equipped with a false bottom made of net gauze $(100 \mu \mathrm{m})$; they were then incubated shaded at in situ temperature $\left(8\right.$ to $9^{\circ} \mathrm{C}$ in May, $14^{\circ} \mathrm{C}$ in July). After $24 \mathrm{~h}$, incubations were stopped by removing the inner compartment. The prosome length of the females was measured under a dissecting microscope. Eggs from each replicate were gently concentrated on a submerged sieve of $20 \mu \mathrm{m}$, immediately counted under a stereo-microscope and incubated on a rolling apparatus ( $1 \mathrm{rpm}$ ) for about $72 \mathrm{~h}$ in $325 \mathrm{ml}$ bottles containing GF/F-filtered ambient seawater. To ensure a sufficiently long incubation time, eggs collected from supplementary experiments were incubated in dishes at the same temperature and monitored daily. Finally, bottle contents were concentrated on a $20 \mu \mathrm{m}$ mesh 


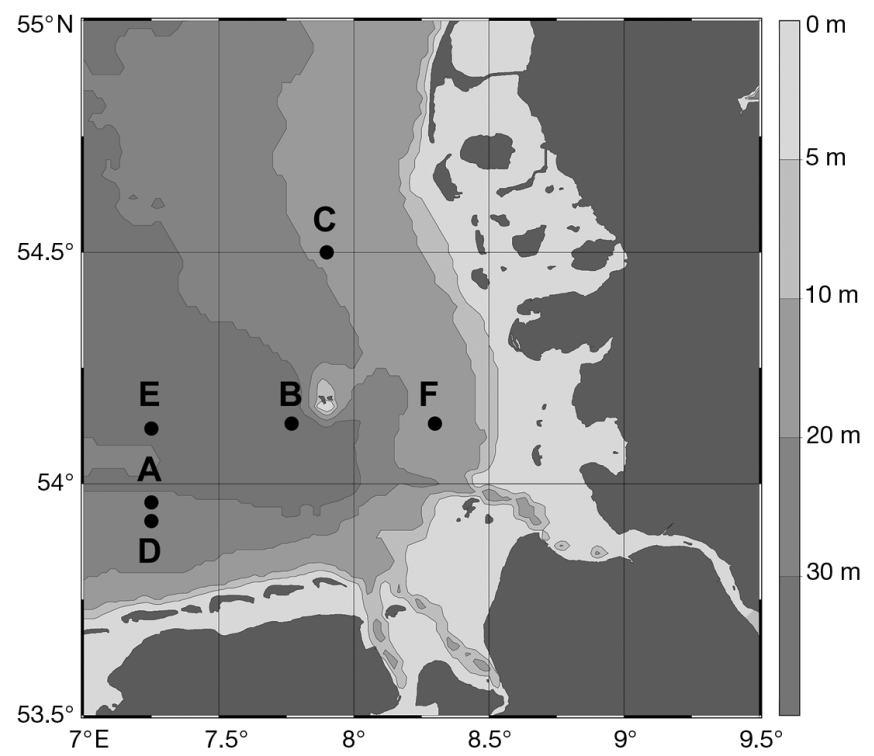

Fig. 1. Map of investigation area, generated with Ocean Data View (ODV) software (Schlitzer 2005); stations sampled in May (Stns A to C) and in July (Stns D to F)

and fixed with Lugol's solution (2\% final concentration). In the laboratory, unhatched eggs, nauplii and empty egg shells were counted under the microscope. Cannibalised eggs, as evidenced by empty shells, accounted for $<5 \%$ of the eggs produced. Egg size was determined in supplementary incubations at each station; at least 30 to 40 eggs were measured. Carbonspecific EPRs were obtained by using carbon-size relationships provided by Dam \& Lopes (2003), assuming a carbon content of $40 \%$ of dry mass.

For lipid analyses females were sorted on net gauze and quickly dried by removing the water below the gauze to minimise salt crusts. Three samples each containing 40 to 50 females of Temora longicornis were immediately frozen at $-80^{\circ} \mathrm{C}$ at each station.

To collect sufficient eggs for lipid analyses, approximately 300 females were incubated in 15 containers (1 l), with a $150 \mu \mathrm{m}$ screened partition in $48 \mu \mathrm{m}$ prescreened water. Every $12 \mathrm{~h}$ in May and $8 \mathrm{~h}$ in July the females were carefully transferred into new containers and the incubation water was filtered through a submerged sieve of $20 \mu \mathrm{m}$ to harvest the eggs. The eggs of each series were rinsed into $20 \mathrm{ml}$ glass vials and stored at 2 to $4^{\circ} \mathrm{C}$ until further processing to slow down development. After $24 \mathrm{~h}$ the eggs were transferred under the stereo-microscope into small vials with GF/F-filtered seawater using an apical thinned-out glass Pasteur pipette. This cleaning procedure was repeated to remove faecal pellets and algal detritus. The eggs were then sorted on precombusted $\left(400^{\circ} \mathrm{C}\right.$ for $12 \mathrm{~h}$ ) GF/C-filters, which were filmed using a digital camera connected to a computer. The images were used to count the eggs in each sample, with an average of 800 eggs filter ${ }^{-1}$. After sorting, the samples were immediately frozen and stored at $-80^{\circ} \mathrm{C}$.

Seston samples were taken with 101 Niskin bottles, and 40 to 601 of water from 5 and $10 \mathrm{~m}$ depths, as well as $15 \mathrm{~m}$ depths at deep stations (Stn B, Stn E), were mixed in equal ratios. During all subsequent preparations, the samples were kept shaded under ambient temperature conditions. Size fractions were produced by using a slow flow-through system of interleaved submerged sieves of 100, 30, 20 and $10 \mu \mathrm{m}$ mesh size to prevent destruction of fragile organisms. After separation, the fractions were carefully resuspended in 1 to 21 of GF/F-filtered seawater. Aliquots were filtered with low pressure (<100 mbar) on precombusted $\left(400^{\circ} \mathrm{C}\right.$ for $\left.12 \mathrm{~h}\right) \mathrm{GF} / \mathrm{C}$ filters for carbon, nitrogen and FA analyses, with 3 replicates each. The filters were immediately frozen and stored at $-80^{\circ} \mathrm{C}$.

Chemical analyses. After lyophilisation, dry mass of females was determined using a micro-balance $( \pm 2 \mu \mathrm{g})$. During weighing procedures, samples were temporarily stored in a vacuum desiccator to prevent unequal condensation on the tissue.

Lipid extraction was performed using ultrasonic disruption in dichloromethane:methanol $(2: 1, \mathrm{v}: \mathrm{v})$ and a washing procedure with aqueous $\mathrm{KCl}$ solution $(0.88 \%)$. For quantification of FAs, tricosanoic acid was added as an internal standard prior to extraction. An additional centrifugation step was carried out prior to the washing procedure for the seston and egg samples to remove GF/C filter remains.

Lipid classes of females were separated by solid phase extraction, using $1 \mathrm{ml} \mathrm{SiOH}$ glass columns (CHROMABOND ${ }^{\circledR}$, Macherey-Nagel) on a vacuum manifold. To remove residues, the columns were washed with a solvent sequence of acetone, diethylether and hexane:diethylether-mixtures, prior to sample load. After column conditioning with $4 \mathrm{ml}$ of hexane, $4 \mu \mathrm{l}$ of lipid extract (lipid concentration approximately $5 \mu \mathrm{g} \mathrm{ll}^{-1}$ ) was added. The neutral lipid fraction was washed out with $2.5 \mathrm{ml}$ hexane:diethylether (95:5, v:v) and $2.5 \mathrm{ml}$ hexane:diethylether $(1: 1, \mathrm{v}: \mathrm{v})$. Polar lipids were eluted with $2.5 \mathrm{ml}$ methanol, and subsequently $5 \mathrm{ml}$ of dichloromethane were added. The polar fraction was then washed with $2 \mathrm{ml}$ aqueous $\mathrm{KCl}$ solution $(0.88 \%)$.

FAs were converted to their methyl ester derivatives (FAMEs) in methanol containing $3 \%$ concentrated sulphuric acid at $80^{\circ} \mathrm{C}$ for $4 \mathrm{~h}$. After cooling, $2 \mathrm{ml}$ of aqua bidest was added, and FAMEs were extracted 3 times with $1 \mathrm{ml}$ hexane. Samples were analysed using a gas chromatograph (HP 6890A) equipped with a DB-FFAP column (30 m length, $0.25 \mathrm{~mm}$ inner diameter, $0.25 \mu \mathrm{m}$ film thickness) operated with a temperature programme and helium as the carrier gas. Samples were 
injected using a programmable temperature vaporiser injector (solvent vent mode). FAMEs and free fatty alcohols were detected by flame ionisation and identified by comparing retention times with those derived from standards of known composition.

Carbon and nitrogen analyses were conducted using a Euro EA (HEKAtech) element analyser.

Statistics. All statistical analyses were performed using the software SPSS. For statistical operations that require normal distribution, percentage data, i.e. relative FA compositions, were transformed using an arcsine/square-root transformation. Differences between measured variables were tested for significance using a 1-way ANOVA followed by a Dunnet-T3 test for post hoc comparisons. Bray-Curtis similarities between the relative FA compositions of seston, eggs and storage lipids of females were calculated on arcsine/squareroot-transformed data using the PRIMER software.

For identification of coherences between egg production, hatching success and FA composition, principal component analyses (PCAs) were performed on the correlation matrix, extracting non-rotated components with eigenvalues $>1$. Only variables with score values more than 0.6 or less than -0.6 were considered for further interpretations. To adjust for temperature differences on the 2 cruises, the specific egg production rate (sEPR) was standardised to a temperature of $10^{\circ} \mathrm{C}$ using a $Q_{10}$ of 3 (Kiørboe \& Sabatini 1995). To describe the impact of food quantity, the first PCA was performed on the standardised egg production, the FA concentration and the POC and PON contents of the total seston and of the size classes 1 to 30 and 30 to $100 \mu \mathrm{m}$. The influence of egg quality was determined by a second PCA using the relative FA composition of the eggs, the standardised egg production and the hatching success. The vector angles between standardised sEPR, hatching success and seston variables, described by the first 2 extracted components, were calculated as a parameter of correlation. Correlations were additionally checked using the non-parametric Spearman rank test.

\section{RESULTS}

\section{Seston}

The total POC concentration varied between 163 and $359 \mu \mathrm{C} \mathrm{C} \mathrm{l}^{-1}$ (Fig. 2a), with maximum amounts in May (Stns A and C) and lowest levels in July (Stns D and E). Highest carbon contents were generally found in the fraction 1 to $10 \mu \mathrm{m}$ (55 to $68 \%$ of total POC). Similarly, the majority of total PON, ranging from $18 \mu \mathrm{g} \mathrm{N} \mathrm{l^{-1 }}$ (Stn D) to $53 \mu \mathrm{g} \mathrm{N}^{-1}$ (Stn A), was observed in the fraction 1 to $10 \mu \mathrm{m}$ (55 to $70 \%$ of total PON). Only at Stn F
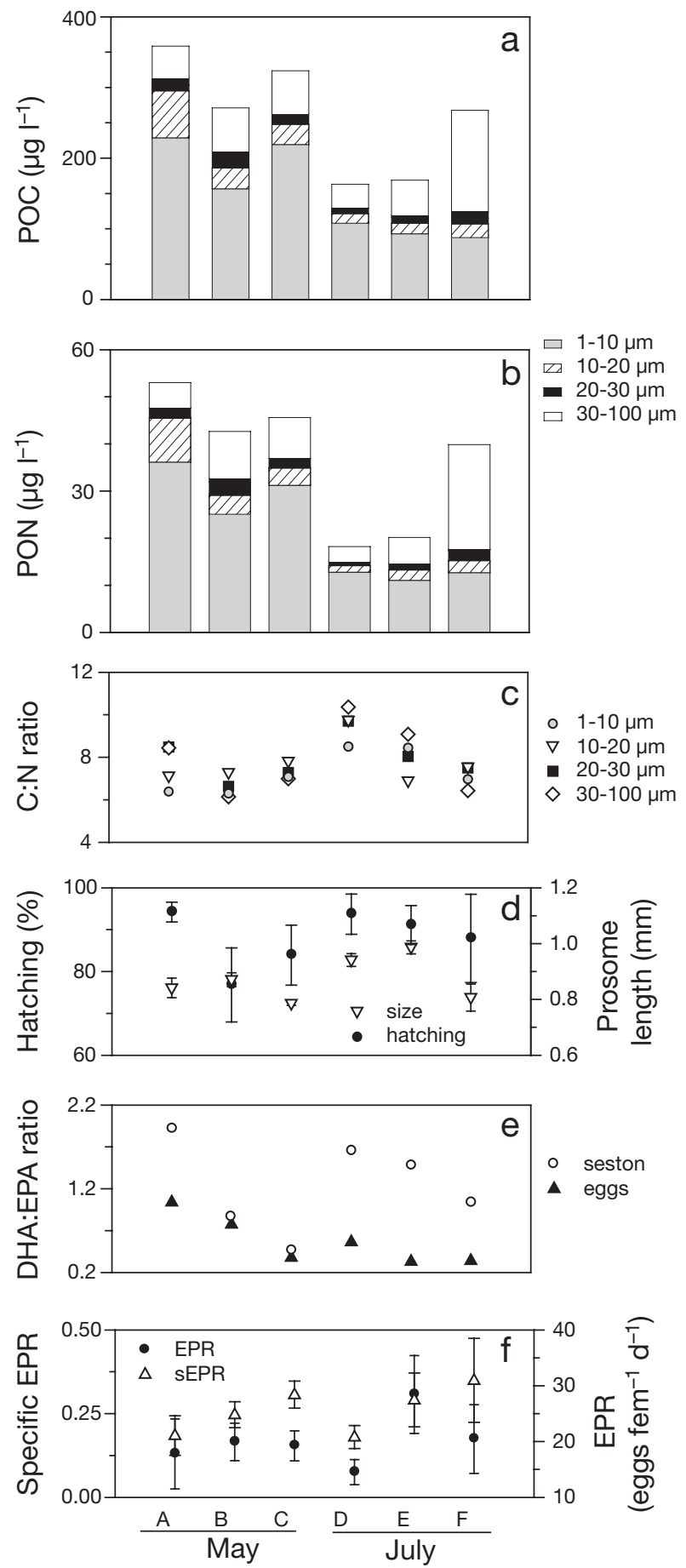

Fig. 2. (a) Concentration of particulate organic carbon (POC) in different size fractions of seston $(n=3)$. (b) Concentration of particulate organic nitrogen (PON) in different size fractions of seston $(n=3)$. (c) Mass ratios of POC and PON in different size fractions of seston $(n=3)$. (d) Hatching success $(\bullet, n=3)$ and prosome length of females of Temora longicornis $(\nabla, \mathrm{n}=28$ to 40 ), with standard deviations (error bars). (e) Docosahexaenoic (DHA):elcosapentaenoic (EPA) ratio of seston (O) and eggs of T. longicornis ( $\mathbf{\Delta})$. (f) T. longicornis individual daily egg production $(E P R, 0)$ and specific egg production rate (sEPR, $\triangle$ ), with standard deviations (error bars, $\mathrm{n}=3$ ). A to $\mathrm{F}$ : Stns A to F 
was $>50 \%$ of PON and POC found in the size class 30 to $100 \mu \mathrm{m}$. The C:N ratio varied from 6.4 (Stn B) to 8.9 (Stn D), corresponding with atomic ratios of 7.9 to 10.4 (Fig. 2c). Lipid content in terms of total FAs and alcohols ranged from 13.8 to $40.8 \mu \mathrm{g}$ total FAs $\mathrm{l}^{-1}$ (Fig. 3b), with significant differences between stations and size classes (ANOVA from $\mathrm{p}=0.000$ to $\mathrm{p}=0.004$ ) and strongly correlated with POC $(r=0.96, p=0.002)$. Fatty alcohols accounted on average for $<4 \%$ of total FAs and alcohols. The FA composition of total seston was characterised by high amounts of 16:0 (19 to $27 \%$ of total FAs), 18:0 (6 to $22 \%), 20: 5(n-3)$ (6 to $22 \%$ ), as well as $16: 1(n-7)$ (5 to $15 \%)$. Relative polyunsaturated fatty acid (PUFA) contents of total seston ranged from $21 \%$ (Stns C and D) up to 37 and $38 \%$ of total FAs (Stns A and $F$, respectively). For some analyses FA data from the different size classes were grouped into the 2 size fractions 1 to 30 and 30 to $100 \mu \mathrm{m}$, since strongest correlations with Temora longicornis were found with the size class 1 to $30 \mu \mathrm{m}$, which most likely represented the
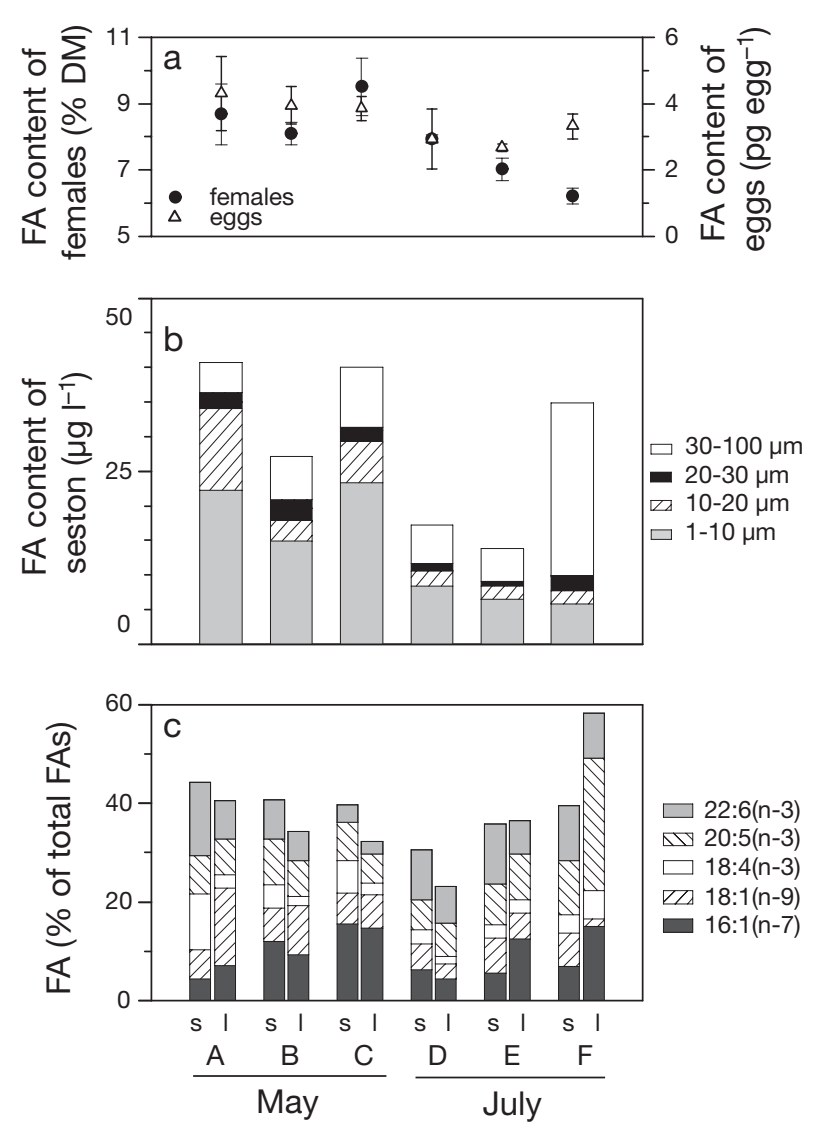

Fig. 3. (a) Total fatty acid (FA) content of Temora longicornis females $(\bullet)$ and eggs $(\triangle)$, with standard deviations (error bars, $\mathrm{n}=3$ ). DM: dry mass. (b) Total FA concentration in different size fractions of seston $(n=3)$. (c) Relative FA composition of seston size fractions 1 to $30 \mu \mathrm{m}$ (s) and 30 to $100 \mu \mathrm{m}(1)$; only signature FAs presented $(n=3)$. A to $F$ : Stns A to F major food source (see section below). In May, elevated levels of the dinoflagellate markers 22:6(n-3) and 18:4(n-3) were observed at Stn A, comprising together $26 \%$ of total FAs in the size class 1 to $30 \mu \mathrm{m}$ (Fig. 3c) and corresponding to a maximum concentration of $9.5 \mathrm{\mu g} \mathrm{l}^{-1}$ (Fig. 4). The diatom marker 16:1(n-7) became more abundant in this size class at the Stns B and C, with 12 and $16 \%$ of FAs, respectively (Fig. 3c) and showed highest concentrations at Stn C, with $6.1 \mathrm{\mu g} \mathrm{l}^{-1}$ (Fig. 4). In July, seston in the 1 to $30 \mu \mathrm{m}$ size fraction was characterised by much lower FA concentrations, while relative proportions of the saturated FAs, as well as $22: 6(n-3)$, were elevated. The size fraction 30 to $100 \mu \mathrm{m}$ showed generally high amounts of saturated FAs, with a peak of 18:1(n-9) at Stn A, as well as very high 20:5(n-3) and 16:1(n-7) values at Stn F in July, comprising together nearly $42 \%$ of all FAs.

\section{Temora longicornis females and eggs}

The lipid content of Temora longicornis females ranged from 6.2 to $9.5 \%$ of dry mass (Fig. 3a) and correlated significantly with the lipid content of the seston in the 1 to $30 \mu \mathrm{m}$ fraction ( $\mathrm{rho}=0.89, \mathrm{p}=0.019$ ), especially with the size class from 1 to $10 \mu \mathrm{m}$ (rho $=1$ ).

The FA composition of total lipids of females showed low variability and was dominated by 16:0 (17 to $19 \%$ of total FAs), 20:5(n-3) (24 to 33\%) and 22:6(n-3) (15 to $24 \%$ ) (data not shown). These FAs are typical membrane components and together comprised 73 to $78 \%$ of the FAs in the polar lipid fraction (data not shown). In contrast, the composition of storage (i.e. neutral) lipids varied more between stations, but basic characteristics were rather constant with 16:0, 16:1(n-7) and 20:5(n-3) as the major FAs at all stations, composing together 50 to $61 \%$ of total FAs in this lipid fraction (Table 1). Most significant differences in the storage lipid composition were found for 16:1(n-7), 18:2(n-6), 18:4(n:3), 20:5(n-3) and 22:6(n-3). In May, 18:4(n-3) and 22:6(n-3) attained maximum values at Stns $A$ and B (Fig. 4), whereas Stn C was characterised by a very high 16:1(n-7) level (25\% of total FAs). The FA 20:5 (n-3) exhibited maximum percentages in July (Stns E and F), with 25 and $31 \%$ of total FAs, respectively (Fig. 4).

Total FA and alcohol content of eggs ranged from 2.6 to $4.3 \mathrm{ng} \mathrm{egg}^{-1}$ (Fig. 3a) and correlated significantly with the total FA content in the seston (rho $=0.83$, $\mathrm{p}=0.042$ ). Based on a mean total FA content of $3.5 \mathrm{ng}$ egg $^{-1}$ and assuming polar lipids as the only FA-containing lipid class (i.e. the mass ratio of FA and non-FA compounds of phosphatidylcholine was applied), as well as a cholesterol content of approximately $10 \%$ of total lipids as found for Acartia sp. (Støttrup et al. 

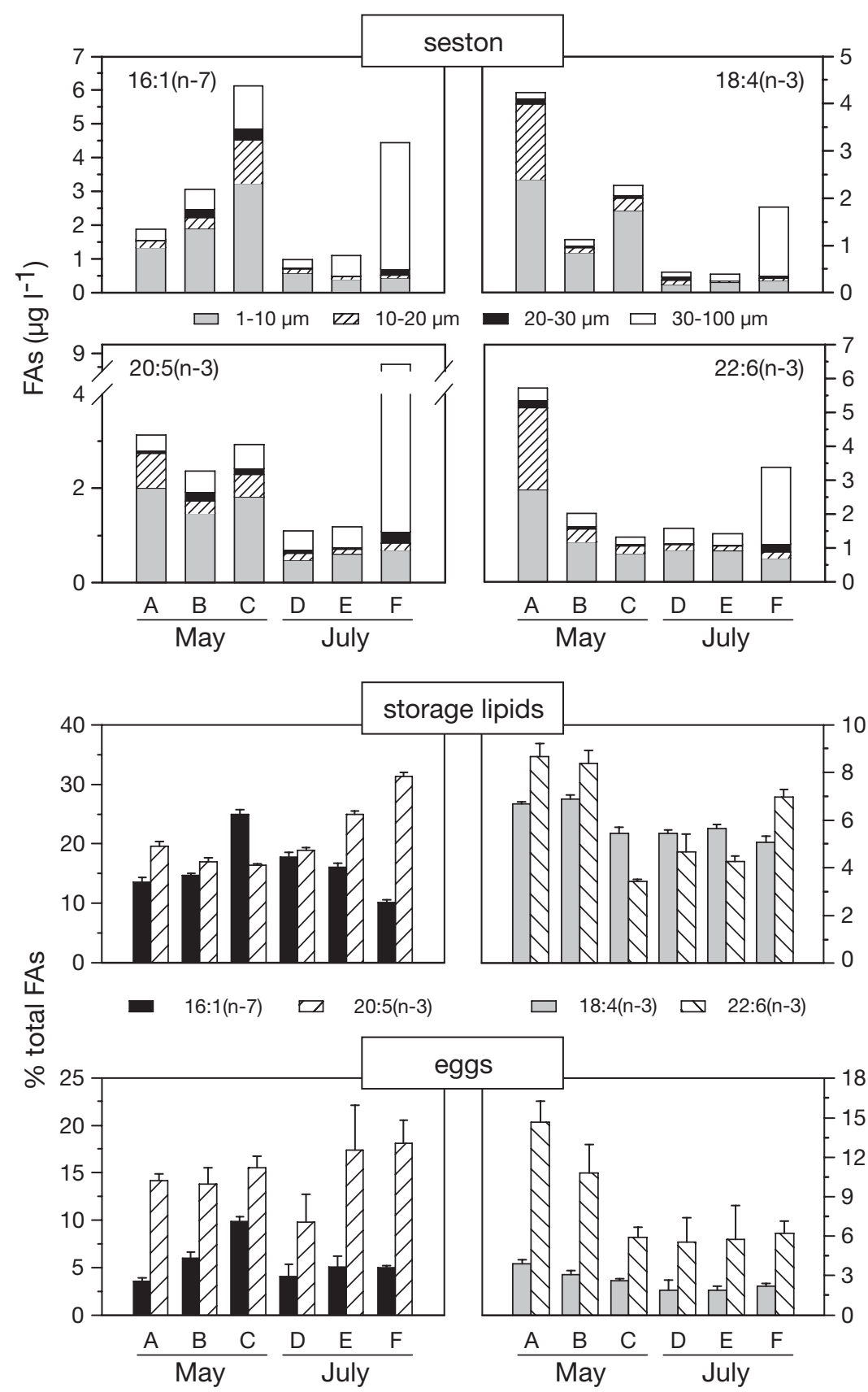

Fig. 4. Concentration of signature fatty acids (FAs) in different size fractions of seston and relative amounts of signature FAs in the storage lipids of Temora longicornis females and eggs $(\mathrm{n}=3)$. A to F: Stns A to F

also showed large amounts of 16:0 and 20:5(n-3), with 19 to 24 and 10 to $18 \%$ of total FAs, respectively (Table 2). Similar to the FA composition of the females, 22:6(n-3) levels were significantly elevated in May (Stns A and B), with up to $15 \%$ of total FAs, as well as $16: 1(\mathrm{n}-7)$, at Stn C (10\% of total FAs) (Fig. 4). The FA 18:0 peaked at Stn D, whereas the Stns E and, especially, F showed the highest 20:5(n-3) levels, similar to the results of the storage lipids of females. No significant correlation was found between the relative FA compositions of females and eggs, except for 18:2(n-6) (rho $=0.87, \mathrm{p}=$ 0.019 ) and 20:5(n-3) (rho $=0.83, \mathrm{p}=$ 0.042), although similar patterns in maximum FAs were observed.

Stronger correlations were found by comparing the FA content of eggs and seston in the 1 to $30 \mu \mathrm{m}$ fraction, as well as the quantitative composition of eggs and seston, especially for 16:1(n-7), 18:4(n-3) and 22:6(n-3) (Fig. 5). A multivariate comparison of the relative FA composition of eggs and females with the seston revealed strong similarities, with the highest consistence between eggs and seston in the size class 1 to $30 \mu \mathrm{m}$ (average Bray-Curtis similarity $91 \%$ ) (Table 3). This strong connection between eggs and the small size class was mainly due to the significant correlations of 16:1(n-7) and 18:4(n-3) (Fig. 5). In contrast, females showed slightly lower similarities with seston composition and more variability in the attribution to the different size classes.

The individual egg production ranged from 14 to 28 eggs female ${ }^{-1} \mathrm{~d}^{-1}$ (Fig. 2d). Due to strong differences in body size (Fig. 2d), sEPR varied strongly from 0.18 to 0.35 (Fig. 2f). In both months, lowest values of sEPR were observed in the southern part of the study area (Stns A and D), while

1999), a maximum total lipid content of $6 \mathrm{ng} \mathrm{egg}^{-1}$ can be estimated. Dry mass is derived from calculated carbon contents of eggs (mean $105 \mathrm{ng} \mathrm{C} \mathrm{egg}^{-1}$ ) assuming carbon to be $45 \%$ of dry mass as found for A. tonsa eggs (Kiørboe et al. 1985). This results in a calculated lipid content of approximately $2.5 \%$ of dry mass.

In contrast to the lipids of females, the variability in the FA composition of the eggs was much higher, but highest production was found in the most northern and eastern stations (Stns C and F, respectively). Egg mortality was generally low, with, on average, 77 to $94 \%$ of all eggs hatching (Fig. 2d). The temperaturestandardised specific egg production rate $\left(\mathrm{sEPR}_{\mathrm{Temp}}\right)$ was negatively correlated with the 22:6(n-3):20:5(n-3) (DHA: EPA) ratio in the seston fraction from 1 to 30 $\mu \mathrm{m}(\mathrm{r}=-0.87, \mathrm{p}=0.024)$, while hatching success was 
Table 1. Temora longicornis. Fatty acid (FA) composition of storage lipids (\% of total FA) of females by sampling period and station. ANOVA describes differences between stations (significance: ${ }^{*} \mathrm{p}<0.05,{ }^{* *} \mathrm{p}<0.01,{ }^{* * *} \mathrm{p}<0.001$ ). FAs with maximum values $<2 \%$ are not shown

\begin{tabular}{|c|c|c|c|c|c|c|c|c|c|c|c|c|c|}
\hline \multirow{3}{*}{ Fatty acid } & \multicolumn{6}{|c|}{ May } & \multicolumn{6}{|c|}{ - July } & \multirow{3}{*}{$\begin{array}{c}\text { ANOVA } \\
\mathrm{p}\end{array}$} \\
\hline & \multicolumn{2}{|c|}{ Stn A } & \multicolumn{2}{|c|}{ Stn B } & \multicolumn{2}{|c|}{ Stn C } & \multicolumn{2}{|c|}{ Stn D } & \multicolumn{2}{|c|}{ Stn E } & \multicolumn{2}{|c|}{ Stn F } & \\
\hline & Mean & $\mathrm{SD}$ & Mean & $\mathrm{SD}$ & Mean & SD & Mean & $\mathrm{SD}$ & Mean & $\mathrm{SD}$ & Mean & $\mathrm{SD}$ & \\
\hline $14: 0$ & 6.3 & 0.2 & 5.9 & 0.3 & 5.9 & 0.5 & 6.7 & 0.9 & 8.4 & 0.7 & 6.4 & 0.1 & ** \\
\hline $16: 0$ & 18.2 & 0.3 & 18.7 & 0.4 & 19.3 & 0.5 & 21.2 & 0.5 & 17.6 & 0.3 & 17.1 & 0.5 & $* * *$ \\
\hline $18: 0$ & 3.3 & 0.3 & 3.3 & 0.2 & 2.6 & 0.1 & 3.3 & 0.1 & 2.9 & 0.2 & 3.2 & 0.2 & ** \\
\hline $16: 1(n-7)$ & 13.5 & 0.8 & 14.7 & 0.4 & 25.0 & 0.7 & 17.7 & 0.8 & 16.1 & 0.6 & 10.1 & 0.4 & $* * *$ \\
\hline $18: 1(n-7)$ & 2.5 & 0.1 & 2.7 & 0.0 & 2.8 & 0.1 & 3.7 & 0.1 & 3.3 & 0.2 & 3.0 & 0.1 & $* * *$ \\
\hline $18: 1(n-9)$ & 3.8 & 0.2 & 4.3 & 0.4 & 3.5 & 0.6 & 3.1 & 0.2 & 2.4 & 0.2 & 2.2 & 0.1 & $* * *$ \\
\hline $18: 2(n-6)$ & 4.2 & 0.1 & 4.4 & 0.0 & 6.3 & 0.3 & 2.0 & 0.0 & 1.2 & 0.0 & 1.7 & 0.0 & $* * *$ \\
\hline $18: 4(n-3)$ & 6.7 & 0.1 & 6.9 & 0.2 & 5.4 & 0.2 & 5.5 & 0.1 & 5.7 & 0.2 & 5.1 & 0.3 & $* * *$ \\
\hline $20: 5(n-3)$ & 19.6 & 0.7 & 16.9 & 0.7 & 16.4 & 0.2 & 18.9 & 0.5 & 24.9 & 0.6 & 31.3 & 0.7 & $* * *$ \\
\hline $22: 6(n-3)$ & 8.7 & 0.5 & 8.4 & 0.5 & 3.4 & 0.1 & 4.7 & 0.7 & 4.3 & 0.2 & 7.0 & 0.3 & $* * *$ \\
\hline
\end{tabular}

Table 2. Temora longicornis. Fatty acid (FA) composition of eggs ( $\%$ of total FA) by sampling period and station. ANOVA describes differences between stations (significance: ${ }^{*} \mathrm{p}<0.05,{ }^{* *} \mathrm{p}<0.01,{ }^{* * *} \mathrm{p}<0.001$ ). FA $<4 \%$ max : FA with maximum values always $<4 \%$ of total FAs

\begin{tabular}{|c|c|c|c|c|c|c|c|c|c|c|c|c|c|}
\hline \multirow{3}{*}{ Fatty acid } & \multicolumn{6}{|c|}{ - May } & \multicolumn{6}{|c|}{ - July } & \multirow{3}{*}{$\begin{array}{c}\text { ANOVA } \\
\mathrm{p}\end{array}$} \\
\hline & \multicolumn{2}{|c|}{ Stn A } & \multicolumn{2}{|c|}{ Stn B } & \multicolumn{2}{|c|}{ Stn C } & \multicolumn{2}{|c|}{ Stn D } & \multicolumn{2}{|c|}{ Stn E } & \multicolumn{2}{|c|}{ Stn F } & \\
\hline & Mean & $\mathrm{SD}$ & Mean & SD & Mean & $\mathrm{SD}$ & Mean & SD & Mean & $\mathrm{SD}$ & Mean & $\mathrm{SD}$ & \\
\hline $14: 0$ & 2.7 & 0.7 & 2.8 & 0.3 & 2.9 & 0.4 & 3.3 & 0.3 & 3.0 & 0.5 & 3.6 & 0.4 & \\
\hline $16: 0$ & 19.2 & 0.4 & 21.0 & 1.1 & 20.9 & 0.3 & 24.1 & 0.7 & 22.2 & 1.1 & 20.4 & 0.6 & $* * *$ \\
\hline $18: 0$ & 8.7 & 0.8 & 8.8 & 0.5 & 7.1 & 0.8 & 15.3 & 1.4 & 10.3 & 1.7 & 8.5 & 1.4 & $* * *$ \\
\hline $16: 1(\mathrm{n}-7)$ & 3.6 & 0.3 & 6.0 & 0.7 & 9.9 & 0.5 & 4.1 & 1.3 & 5.1 & 1.1 & 5.0 & 0.2 & $* * *$ \\
\hline 18:1(n-7) & 1.8 & 0.0 & 2.5 & 0.1 & 3.1 & 0.2 & 2.6 & 0.2 & 3.0 & 0.5 & 3.4 & 0.6 & ** \\
\hline $18: 1(\mathrm{n}-9)$ & 5.9 & 0.1 & 7.3 & 0.7 & 7.4 & 0.8 & 7.9 & 3.0 & 8.1 & 1.9 & 10.2 & 5.8 & \\
\hline $18: 2(\mathrm{n}-6)$ & 4.1 & 0.2 & 4.4 & 0.5 & 5.2 & 0.3 & 3.7 & 0.8 & 3.0 & 0.6 & 4.0 & 1.6 & \\
\hline $18: 4(\mathrm{n}-3)$ & 3.9 & 0.3 & 3.0 & 0.3 & 2.6 & 0.2 & 1.9 & 0.8 & 1.9 & 0.3 & 2.2 & 0.2 & ** \\
\hline $20: 5(n-3)$ & 14.1 & 0.8 & 13.8 & 1.7 & 15.5 & 1.2 & 9.8 & 3.0 & 17.4 & 4.7 & 18.1 & 2.4 & * \\
\hline $22: 6(n-3)$ & 14.7 & 1.6 & 10.8 & 2.2 & 5.9 & 0.7 & 5.6 & 1.8 & 5.8 & 2.6 & 6.2 & 0.9 & $* * *$ \\
\hline $\mathrm{FA}<4 \%$ max & 21.3 & 0.9 & 19.6 & 4.2 & 19.5 & 0.7 & 21.8 & 3.0 & 20.4 & 3.9 & 18.3 & 2.7 & \\
\hline
\end{tabular}

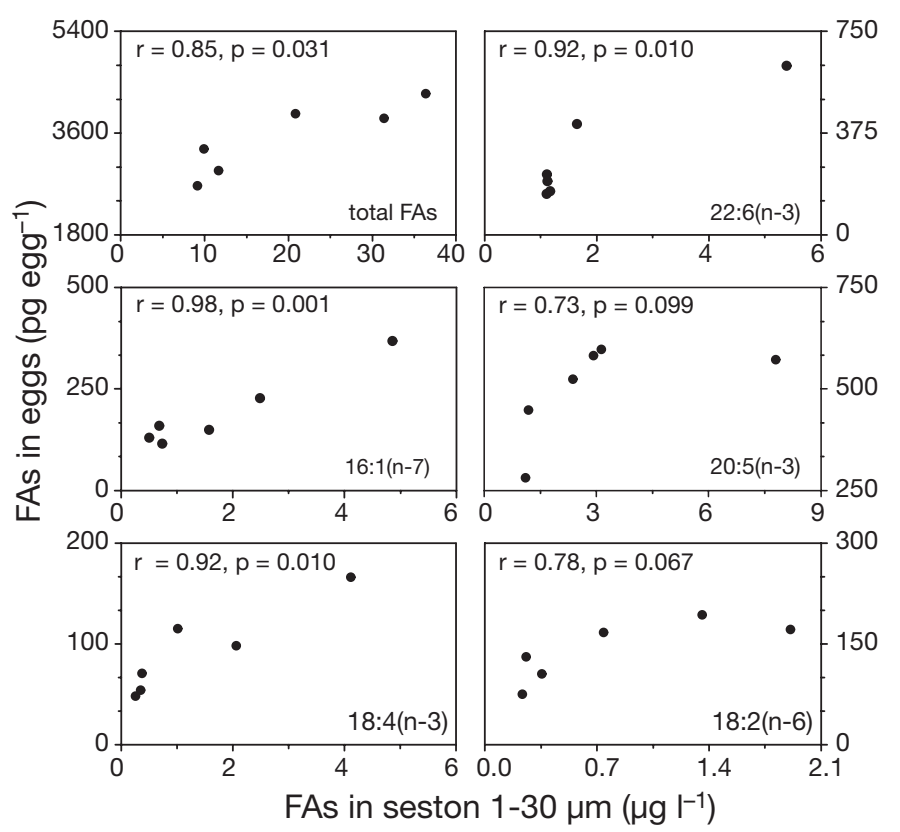

positively rank-correlated with the DHA:EPA ratio (rho $=0.94, \mathrm{p}=0.005$ ). However, we did not find any relation of egg production or hatching success to the DHA:EPA ratios of the eggs. No correlations were found with the (n-6):(n-3) ratios in the seston or the eggs.

The first PCA on egg production and quantitative seston constituents revealed a strong dependency of the $\mathrm{sEPR}_{\mathrm{Temp}}$ on the POC and PON concentration of total seston, as well as on the content of 16:0, as the major seston component (Table 4). Most coherences were found with FAs in total seston, namely 18:4(n-3), 18:1(n-9) and 18:1(n-7), as well as with FAs in the size class 1 to $30 \mu \mathrm{m}$, especially 20:5(n-3) and 16:1(n-7). A

Fig. 5. Correlation between fatty acid (FA) amounts in the eggs of Temora longicornis and their concentration in the seston size fraction 1 to $30 \mu \mathrm{m}$ 
Table 3. Bray-Curtis similarity (\%) between relative fatty acid composition of Temora longicornis eggs and size-fractionated seston and between neutral lipids of $T$. longicornis females and size-fractionated seston (based on arcsine/square-roottransformed data) by sampling period and station (Stns A to F)

\begin{tabular}{|c|c|c|c|c|c|c|}
\hline & \multicolumn{3}{|c|}{ — May — } & \multicolumn{3}{|c|}{ _uly } \\
\hline & A & B & $\mathrm{C}$ & D & E & $\mathrm{F}$ \\
\hline \multicolumn{7}{|c|}{ Eggs vs. seston } \\
\hline $1-30 \mu \mathrm{m}$ & 90.3 & 90.3 & 89.6 & 91.0 & 91.0 & 90.7 \\
\hline $30-100 \mu \mathrm{m}$ & 86.6 & 87.9 & 86.1 & 89.2 & 87.6 & 78.4 \\
\hline \multicolumn{7}{|c|}{ Females vs. seston } \\
\hline $1-30 \mu \mathrm{m}$ & 88.2 & 90.6 & 89.0 & 81.8 & 77.8 & 84.1 \\
\hline $30-100 \mu \mathrm{m}$ & 82.8 & 83.7 & 82.6 & 77.9 & 84.1 & 89.8 \\
\hline
\end{tabular}

Table 4. Principal component (PC) analysis, loadings of variables (absolute values of seston) on PC1. Bold: significant Spearman rank correlations $(\mathrm{p}<0.05)$. $\mathrm{sEPR}_{\mathrm{Temp}}$ : temperature-standardised egg production rate; alpha: angle between vectors described by $\mathrm{PC} 1$ and $\mathrm{PC} 2$

\begin{tabular}{|c|c|c|}
\hline Seston $\left(\mu g \mathrm{l}^{-1}\right)$ & PC1 $(51.4 \%)$ & Alpha \\
\hline $\mathrm{sEPR}_{\mathrm{Temp}}$ & 0.73 & - \\
\hline POC total & 0.91 & 0 \\
\hline PON total & 0.87 & 5 \\
\hline $18: 4(n-3)$ total & 0.82 & 5 \\
\hline 16:0 total & 0.87 & 6 \\
\hline 18:1(n-9) 30-100 $\mu \mathrm{m}$ & 0.92 & 9 \\
\hline $20: 5(n-3) 1-30 \mu m$ & 0.99 & 19 \\
\hline 18:1(n-9) total & 1.00 & 22 \\
\hline $18: 1(n-7)$ total & 0.97 & 23 \\
\hline 16:1(n-7) $1-30 \mu \mathrm{m}$ & 0.75 & 24 \\
\hline PON 1-30 $\mu \mathrm{m}$ & 0.98 & 24 \\
\hline 18:1(n-9) $1-30 \mu \mathrm{m}$ & 1.00 & 26 \\
\hline $18: 1(n-7) 1-30 \mu \mathrm{m}$ & 0.97 & 26 \\
\hline $18: 2(n-6)$ total & 0.97 & 26 \\
\hline $14: 01-30 \mu \mathrm{m}$ & 0.99 & 28 \\
\hline $18: 4(n-3) 1-30 \mu m$ & 0.89 & 28 \\
\hline POC $1-30 \mu \mathrm{m}$ & 0.98 & 28 \\
\hline $14: 0$ total & 0.98 & 29 \\
\hline $18: 2(n-6) 1-30 \mu \mathrm{m}$ & 0.95 & 30 \\
\hline $16: 01-30 \mu \mathrm{m}$ & 0.96 & 32 \\
\hline $22: 6(n-3) 1-30 \mu m$ & 0.62 & 32 \\
\hline
\end{tabular}

second PCA on the FA composition of eggs revealed a positive relation of egg production with the levels of 18:2(n-6), 16:1(n-7) and 20:5(n-3) in the eggs, as well as a negative relation to the FAs $16: 0$ and $18: 0$ and hatching success. Accordingly, levels of 16:1(n-7) (rho = $-0.89, p=0.019$ ) and 20:5(n-3) in the eggs showed a negative correlation with hatching success (Table 5). The absolute amount of 16:1(n-7) in the eggs correlated positively with $\mathrm{sEPR}_{\mathrm{Temp}}(\mathrm{r}=-0.93, \mathrm{p}=0.006)$, as well with the $\mathrm{SEPR}_{\mathrm{Temp}}$ that included only viable eggs ( $r=-0.92, p=0.01$ ) (Fig. 6).
Table 5. Principal component (PC) analysis, loadings of fatty acids in the eggs of Temora longicornis (\% of total fatty acids), standardised egg production rates and hatching success on PC1 and PC2. Bold: significant Spearman rank correlations $(p<0.05) . s E P R_{T e m p}$ : temperature-standardised egg production rate; alpha: angle between vectors described by $\mathrm{PC} 1$ and $\mathrm{PC} 2 . \%=$ variance explained by PC1 and PC2

\begin{tabular}{|c|c|c|}
\hline & PC1 (43.5\%) & Alpha \\
\hline $\mathrm{sEPR}_{\mathrm{Temp}}$ & -0.76 & - \\
\hline $18: 2(n-6)$ & -0.68 & 11 \\
\hline $18: 4(n-3)$ & -0.92 & 58 \\
\hline $22: 6(n-3)$ & -0.76 & 75 \\
\hline $18: 1(n-9)$ & 0.65 & 97 \\
\hline $14: 0$ & 0.75 & 114 \\
\hline $16: 0$ & 0.81 & 148 \\
\hline \multirow[t]{2}{*}{ 18:0 } & 0.76 & 177 \\
\hline & PC2 (33.7\%) & Alpha \\
\hline $\mathrm{sEPR}_{\mathrm{Temp}}$ & 0.61 & - \\
\hline $16: 1(n-7)$ & 0.80 & 30 \\
\hline $20: 5(n-3)$ & 0.62 & 35 \\
\hline $18: 1(n-7)$ & 0.89 & 79 \\
\hline $18: 1(n-9)$ & 0.65 & 97 \\
\hline \multirow[t]{2}{*}{ Hatching success } & -0.66 & 161 \\
\hline & PC2 (33.7\%) & Alpha \\
\hline Hatching success & -0.66 & - \\
\hline $18: 1(n-9)$ & 0.65 & 103 \\
\hline $18: 1(n-7)$ & 0.89 & 121 \\
\hline $\mathrm{sEPR}_{\mathrm{Temp}}$ & 0.61 & 161 \\
\hline $20: 5(n-3)$ & 0.62 & 165 \\
\hline $16: 1(n-7)$ & 0.80 & 170 \\
\hline
\end{tabular}

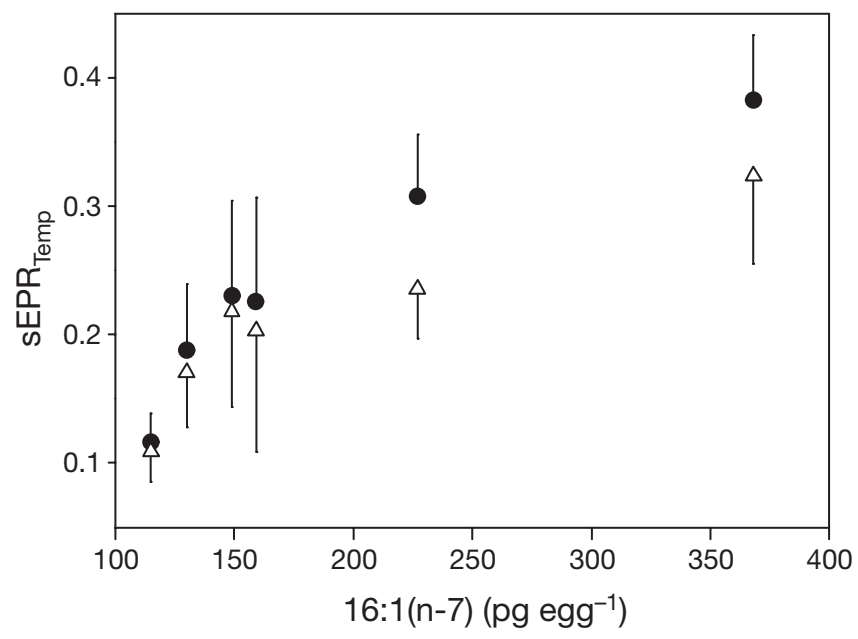

Fig. 6. Temora longicornis. Correlation between 16:1(n-7) $\left(\mathrm{pg} \mathrm{egg}^{-1}\right)$ and the specific temperature-standardised egg production rate $\left(\mathrm{sEPR}_{\mathrm{Temp}}\right)(\bullet)$ and the $\mathrm{sEPR}$ Temp that included only the viable eggs produced $(\Delta)$, with standard deviations (error bars, $\mathrm{n}=3$ ) 


\section{DISCUSSION}

Recent studies emphasise the importance of food quality for growth and reproductive success of copepods, and special importance is attached to the role of essential FAs (Jónasdóttir et al. 1995, Pond et al. 1996, Shin et al. 2003, Arendt et al. 2005). However, the relevance of essential FAs for egg production and hatching success of copepods in marine systems is yet poorly understood and based on observed correlations between reproductive success and FA composition of bulk seston measurements. Even though these correlations indicate nutritional regulation, they do not necessarily provide information on the underlying causal relationships. Further insight into the mechanisms that determine reproductive success might be obtained by elucidating the coupling of food composition with egg quality and the consequences for hatching success. Hence, our field study focused on the transfer of dietary FAs into the eggs and aimed at assessing their potential as limiting factors for the egg production and egg viability of Temora longicornis in the North Sea.

Signature FAs were used to analyse the feeding history of Temora longicornis females, and, in order to obtain mostly unaltered signals, we specifically focused on the FA composition of storage, i.e. neutral, lipids. Elevated values of 22:6(n-3) and to a minor degree of 18:4(n-3) most likely reflect an ingestion of dinoflagellates or cryptophytes in May, while constantly high levels of 16:1(n-7) and 20:5(n-3) indicate that diatoms contributed strongly to the diet (Daalsgard et al. 2003 and references therein). Although the FA compositions of neutral lipids of females and eggs were rather uniform, the profiles still differed significantly between stations and displayed strong correlations with seston lipids, emphasising that sampled seston was actually the food used to build up the eggs. Thus, diet composition was reflected rather quickly in the eggs, expressing the high physiological turnover rates in females. Laboratory studies demonstrated that labelled carbon can be detected in oocytes of T. longicornis $24 \mathrm{~h}$ after ingestion (Smith \& Hall 1980); basically similar transfer rates are to be expected for FAs.

A strong dietary influence on the FA composition of the eggs and nauplii of Acartia tonsa and Calanus helgolandicus has been shown in laboratory experiments (Ederington et al. 1995, Støttrup et al. 1999, Lacoste et al. 2001). Comparisons between FA patterns of eggs and food might therefore be used to describe food selectivity. While Pond et al. (1996) did not record high similarities between FA profiles of seston and C. helgolandicus eggs and ascribed this to selective feeding behaviour, similarities were extremely high in our study, especially with the FA profiles of the 1 to $30 \mu \mathrm{m}$ fraction seston. The correlation observed be- tween the FA content of females and of 1 to $10 \mu \mathrm{m}$ seston, as well as between FA levels in the eggs and in the 1 to $30 \mu \mathrm{m}$ seston, further indicate a primarily use of the size fraction $<30 \mu \mathrm{m}$. Since the majority of POC was found in these small size fractions and since we detected no preference for larger food particles, Temora longicornis most likely fed non-selectively during our study.

Mean daily egg production ranged from 14 to 28 eggs female ${ }^{-1}$. Maximum daily rates in the North Sea can increase up to 62 eggs in May (Halsband \& Hirche 2001) and 77 eggs in April (Arendt et al. 2005); hence, individual EPRs were rather moderate. In contrast, sEPRs were high and varied strongly within the investigation area, but still did not approach maximum values (Halsband \& Hirche 2001, Arendt et al. 2005). Therefore, egg production was most likely limited during our study. sEPRs showed similar ranges in both months, although feeding conditions, as indicated by POC and PON levels, strongly differed. However, if the temperature difference of both months is taken into account, we observed a strong correlation of $\mathrm{sEPR}_{\text {Temp }}$ with POC and PON contents, as well as with the levels of 16:0, 18:4(n-3) and 18:1 isomers in the seston. This indicated that the food amount most likely determined productivity of Temora longicornis during the investigation period.

A positive relationship between $s E P R_{\text {Temp }}$ and the diatom markers in the 1 to $30 \mu \mathrm{m}$ seston indicated that diatoms provided an important food source for production at that time, as was also reflected in the FA profiles of the eggs. However, not only the proportion of diatom markers in the eggs, but, to a lesser degree, also that of dinoflagellate markers were associated with $\mathrm{sEPR}_{\text {Temp. }}$. Therefore, increased food signals in the eggs coincided with enhanced egg production. The latter was positively correlated with the relative 18:2(n-6) content in the eggs. This FA was related to the hatching success of Calanus helgolandicus (Pond et al. 1996), suggesting that 18:2(n-6) might play an important role during egg development.

While the DHA:EPA ratio in the seston correlated negatively with egg production, we found a positive relationship with hatching success. Similar correlations between DHA:EPA ratios in the diet and egg viability of Temora longicornis were reported from a field study in the North Sea (Arendt et al. 2005). However, DHA:EPA ratios in the eggs did not suggest a coherence of both variables. Hence, this commonly used FA ratio is more likely an indicator of specific feeding conditions in the field, rather than a quality attribute of the diet that directly affects egg viability. Low DHA:EPA ratios in the seston reflect high proportions of diatoms, which, in turn, might adversely affect the hatching success of non-selective feeders. The detected nega- 
tive correlation between the diatom marker 16:1(n-7) in the eggs and their viability supports this assumption. Previous studies in the North Sea reported similar coherences, where high proportions of 16:1(n-7) in the seston coincided with increased egg mortality in T. longicornis (Arendt et al. 2005) and Calanus finmarchicus (Jónasdóttir et al. 2002). However, egg viability was overall high at all our stations. Since we found no significant correlation of hatching success with changes in total FA content or essential FA levels in the eggs, lipids were obviously transferred in sufficient quantities or even in excess of the requirements. Hence, the slight, but significant, negative influence of diatoms on hatching success might be explained by minor nutritional deficiencies of non-FA-components. Diatoms have been found to provide insufficient amounts of sterol in experiments; hence, diatom blooms could present conditions under which dietary sterol limitation becomes possible (Hasset 2004). However, the tendency to produce less viable eggs on a diatom-dominated diet was clearly compensated by the strong increase in egg production with increasing diatom food supply. Thus, food quantity rather than quality determined the reproductive success of T. longicornis during our study.

Despite the overall importance of food quantity, a largely unexplained correlation occurred between dietary FAs and reproductive success. Whether this correlation reflects a causal relationship, i.e. FAs limited the production of Temora longicornis, might be assessed using a stoichiometric approach. A prediction of food availability from bulk measurements of seston is problematic, since carbon and nitrogen might originate from inaccessible sources like small particles or detritus. However, minimum demands for nutritional components can be estimated, assuming a hypothetical $100 \%$ accessibility in the seston and a gross growth efficiency (GGE) from the literature (Peterson \& Dam 1996). Calculated N:PUFA ratios (egg nitrogen content according to Dam \& Lopes 2003) were found to be much lower in seston (mean ratio $=5$ ) than in eggs (mean ratio $=18$ ). Hence, GGE for PUFAs deduced from nitrogen demands and $\mathrm{N}$ :PUFA ratios were extremely low, ranging between 0.02 and 0.07. Since PUFAs abound in seston compared to nitrogen and are most likely accessible in higher proportions, as they mainly originate from living organisms, we suggest that nitrogen-containing compounds might have had a higher potential for limiting egg production during our study than essential FAs. Similarly, an inefficient transfer of dietary proteins into the eggs was suggested for Acartia tonsa (Kleppel \& Hazzard 2000). However, as we do not know the maximum growth efficiencies of $T$. longicornis for the different nutritional compounds, identified limitation factors based on stoichiometry should be interpreted with caution (e.g. Tang \& Dam 1999).

Further indications for the limitation potential of FAs on egg production might be derived from the transfer of specific FAs into the eggs. FA levels in the eggs were related to their concentrations in the seston, thus indicating only minor maternal regulation. Hence, hatching success rather than egg production should be affected more strongly in times of low availability of essential FAs, unless maternal regulation starts to increase with increasing dietary deficiencies. Values of 22:6(n-3) previously recorded in the North Sea were $>10$ times lower than in the present study and were associated with low hatching success in Temora longicornis (Arendt et al. 2005). Still, extremely low 22:6(n-3) values often coincide with low food supply (Arendt et al. 2005) and will consequently lead to lower egg production with lower FA demands.

The generally low FA demand for the production of eggs is associated with the extremely low lipid content. Similar low lipid values were found for Acartia tonsa eggs with only $1.2 \mathrm{ng}$ total FAs egg $^{-1}$ in the field (Hazzard \& Kleppel 2003) and 6 ng unsaturated FAs egg $^{-1}$ in an experimental study (Drillet et al. 2006). Other copepod species are known to transfer large lipid depots into the eggs, leading to egg lipid contents of $35 \%$ of dry mass in Calanus helgolandicus (Guisande \& Harris 1995) and up to $93 \%$ in Paraeuchaeta polaris (Auel 2004). In contrast, eggs of Temora longicornis obviously do not rely strongly on lipids as an energy source. This is conclusive, considering the fast embryonic development of T. longicornis, e.g. $2.7 \mathrm{~d}$ from egg to nauplius stage II (NII) at $10^{\circ} \mathrm{C}$ in the North Sea (Halsband-Lenk et al. 2002). The ontogenetically early onset of feeding in NII (Klein Breteler et al. 1990) reduces the need for long-lasting maternal energy supplies. Guisande \& Harris (1995) found relatively high levels of carbohydrates in eggs of C. helgolandicus (up to $13 \%$ of dry mass), which decreased during embryonic development. This energy source can rapidly be used and might therefore be advantageous for fast-developing eggs and nauplii. In conclusion, it seems likely that non-FA components like carbohydrates, proteins, glyco-compounds, or sterols play an important role in the embryonic development of $T$. longicornis and might thus strongly affect reproductive success.

Acknowledgements. The study was funded by the German Federal Ministry for Education and Research within the GLOBEC GERMANY project (03F0418C). We thank the crews and scientific parties of the RV 'Heincke' and 'Poseidon' for excellent support during the field phase. We also thank B. Niehoff and C. v. Waldthausen for C:N measurements. H. Auel and D. Stübing are gratefully acknowledged for the valuable discussions on this data, which improved the manuscript. 


\section{LITERATURE CITED}

Anderson TR, Pond DW (2000) Stoichiometric theory extended to micronutrients: comparison of the roles of essential fatty acids, carbon, and nitrogen in the nutrition of marine copepods. Limnol Oceanogr 45:1162-1167

Arendt KE, Jónasdóttir SH, Hansen PJ, Gärtner S (2005) Effects of dietary fatty acids on the reproductive success of the calanoid copepod Temora longicornis. Mar Biol 146: $513-530$

Auel H (2004) Egg size and reproductive adaptations among Arctic deep-sea copepods (Calanoida, Paraeuchaeta). Helgol Mar Res 58:147-153

Daalsgard J, St. John M, Kattner G, Müller-Navarra D, Hagen W (2003) Fatty acid trophic markers in the pelagic marine environment. Adv Mar Biol 46:225-340

Dam HG, Lopes RM (2003) Omnivory in the calanoid copepod Temora longicornis: feeding, egg production and egg hatching rates. J Exp Mar Biol Ecol 292:119-137

Dam HG, Peterson WT (1993) Seasonal contrasts in the diel vertical distribution, feeding behaviour, and grazing impact of the copepod Temora longicornis in Long Island Sound. J Mar Res 51:561-594

Drillet G, Iversen MH, Sørensen TF, Ramløv H, Lund T, Hansen BW (2006) Effect of cold storage upon eggs of a calanoid copepod Acartia tonsa (Dana) and their offspring. Aquaculture 254:714-729

Ederington MC, McManus GB, Harvey HR (1995) Trophic transfer of fatty acids, sterols, and triterpenoid alcohol between bacteria, a ciliate, and the copepod Acartia tonsa. Limnol Oceanogr 40:860-867

Guisande C, Harris R (1995) Effect of total organic content of eggs on hatching success and naupliar survival in the copepod Calanus helgolandicus. Limnol Oceanogr 40:476-482

Guisande C, Riveiro I, Maneiro I (2000) Comparisons among the amino acid composition of females, eggs and food to determine the relative importance of food quantity and food quality to copepod reproduction. Mar Ecol Prog Ser 202: 135-142

Halsband C, Hirche HJ (2001) Reproductive cycles of dominant calanoid copepods in the North Sea. Mar Ecol Prog Ser 209: 219-229

Halsband-Lenk C, Hirche H-J, Carlotti F (2002) Temperature impact on reproduction and development of congener copepod populations. J Exp Mar Biol Ecol 271:121-153

Hasset RP (2004) Supplementation of a diatom diet with cholesterol can enhance copepod egg production rates. Limnol Oceanogr 49:488-494

Hazzard SE, Kleppel GS (2003) Egg production of the copepod Acartia tonsa in Florida Bay: role of fatty acids in the nutritional composition of the food environment. Mar Ecol Prog Ser 252:199-206

Helland S, Nejstgaard JC, Humlen R, Fyhn HJ, Båmstedt U (2003) Effect of season and maternal food on Calanus finmarchicus reproduction, with emphasis on free amino acids. Mar Biol 142:1141-1151

Jónasdóttir SH, Fields D, Pantoja S (1995) Copepod egg production in Long Island Sound, USA, as a function of the chemical composition of seston. Mar Ecol Prog Ser 119:87-98

Jónasdóttir SH, Gudfinnsson HG, Gislason A, Astthorsson OS (2002) Diet composition and quality for Calanus finmarchi-

Editorial responsibility: Howard Browman (Associate Editorin-Chief), Storebø, Norway cus egg production and hatching success off south-west Iceland. Mar Biol 140:1195-1206

Kiørboe T, Sabatini M (1995) Scaling of fecundity, growth and development in marine planktonic copepods. Mar Ecol Prog Ser 120:285-298

Kiørboe T, Møhlenberg F, Hamburger K (1985) Bioenergetics of the planktonic copepod Acartia tonsa: relation between feeding, egg production and respiration, and composition of specific dynamic action. Mar Ecol Prog Ser 26:85-97

Klein Breteler WCM, Schogt N, Gonzalez SR (1990) On the role of food quality in grazing and development of life stages, and genetic change of body size during cultivation of pelagic copepods. J Exp Mar Biol Ecol 135:177-189

Kleppel GS (1992) Environmental regulation of feeding and egg production by Acartia tonsa off southern California. Mar Biol 112:57-65

Kleppel GS, Hazzard SE (2000) Diet and egg production of the copepod Acartia tonsa in Florida Bay. II. Role of the nutritional environment. Mar Biol 137:111-121

Lacoste A, Poulet SA, Cueff A, Kattner G, Ianora A, Laabir M (2001) New evidence of the copepod maternal food effects on reproduction. J Exp Mar Biol Ecol 259:85-107

Maps F, Runge JA, Zakardjian B, Joly P (2005) Egg production and hatching success of Temora longicornis (Copepoda, Calanoida) in the southern Gulf of St. Lawrence. Mar Ecol Prog Ser 285:117-128

Peterson WT, Dam HG (1996) Pigment ingestion and egg production rates of the calanoid copepod Temora longicornis: implications for gut pigmet loss and omnivorous feeding. J Plankton Res 18:855-861

Pond D, Harris R, Head R, Harbour D (1996) Environmental and nutritional factors determining seasonal variability in the fecundity and egg viability of Calanus helgolandicus in coastal waters off Plymouth, UK. Mar Ecol Prog Ser 143: $45-63$

Rowley AF, Vogan CL, Taylor GW, Clare AS (2005) Prostaglandins in non-insectan invertebrates: recent insights and unsolved problems. J Exp Biol 208:3-14

Sargent J, McEvoy L, Estevez A, Bell G, Bell M, Henderson J, Tocher D (1999) Lipid nutrition of marine fish during early development: current status and future directions. Aquaculture 179:217-229

Schlitzer R (2005) Ocean data view. Available at: www.awibremerhaven.de/GEO/ODV

Shin K, Jang MC, Jang PK, Ju SJ, Lee TK, Chang M (2003) Influence of food quality on egg production and viability of the marine planktonic copepod Acartia omorii. Prog Oceanogr 57:265-277

Smith SL, Hall BK (1980) Transfer of radioactive carbon within the copepod Temora longicornis. Mar Biol 55: $277-286$

Støttrup JG, Bell JG, Sargent JR (1999) The fate of lipids during development and cold-storage of eggs in the laboratory-reared calanoid copepod, Acartia tonsa Dana, and in response to different algal diets. Aquaculture 176:257-269

Tang KW, Dam HG (1999) Limitation of zooplankton production: beyond stoichiometry. Oikos 84:537-542

Tang KW, Taal M (2005) Trophic modification of food quality by heterotrophic protists: species-specific effects on copepod egg production and egg hatching. J Exp Mar Biol Ecol 318: $85-98$

Submitted: May 24, 2006; Accepted: November 3, 2006

Proofs received from author(s): June 19, 2007 